\title{
The determinants of knowledge of cervical cancer, attitude towards screening and practice of cervical cancer prevention amongst antenatal attendees in Ibadan, Southwest Nigeria
}

\author{
Adebayo M D Agboola ${ }^{1}$ and Oluwasomidoyin O Bello² \\ ${ }^{1}$ Department of Obstetrics and Gynaecology, University College Hospital, University of Ibadan, PMB 5116, Ibadan, Oyo State, Nigeria \\ ${ }^{2}$ Department of Obstetrics and Gynaecology, College of Medicine, University College Hospital, University of Ibadan, PMB 5116, Ibadan, Oyo State, Nigeria
}

\section{Abstract}

Cervical cancer (CC) is an extremely preventable and curable disease with early detection and treatment. Unfortunately, the practice of cervical cancer prevention (CCP) remains poor in resource constrained countries. This study aimed to identify determinants of knowledge of CC, attitude towards cervical cancer screening (CCS) and practice of CCP among antenatal attendees in a tertiary hospital in Southwest Nigeria as they are sexually active women. This was a cross-sectional survey of a cohort of 287 antenatal attendees using a self-administered structured questionnaire to assess their knowledge of CC, attitude towards screening and uptake of screening and human papillomaviruses (HPVs) vaccination as methods of practice of CCP. Data was analysed using the Statistical Package for Social Sciences version 20.0. Descriptive statistics were conducted for all relevant data. Categorical variables were explored using chi-square test and the independent variables with significant associations ( $p$-value $<0.05$ ) entered into logistic regression analysis. The mean age was $30.62 \pm 4.5$ years. Three-fifths $(60.6 \%)$ of the women had good knowledge of CC while $47.4 \%$ had heard about CCS. Majority (75.6\%) were willing to undergo CCS thereby exhibiting positive attitude towards screening. The practice of CCP was poor as only 27 (9.4\%) had ever been screened for CC while 10 (3.5\%) had received the HPV vaccine. Interestingly, none of the women who had received the HPV vaccine had been screened for CC. Those with tertiary education were more likely (OR = $2.140,95 \% \mathrm{Cl}=1.166-4.979$ ) to exhibit positive attitude to CCS, while those with poor knowledge were about two times less likely to have a positive attitude (OR $=0.532,95 \%$ $\mathrm{Cl}=0.291-0.972)$. Poor knowledge of CC was associated with lesser odds $(O R=0.061$, $95 \% \mathrm{Cl}=0.008-0.471$ ) of practice of CCP. In Nigeria, the burden of CC can be reduced if women are educated and health care providers challenged to recommend CCS and HPV vaccination.

Keywords: cervical cancer, antenatal attendees, Pap smear, cervical cancer screening, cervical cancer prevention, Nigeria
Correspondence to: Adebayo M D Agboola Email: agboolamd123@gmail.com

ecancer 2021, 15:1225

https://doi.org/10.3332/ecancer.2021.1225

Published: 05/05/2021

Received: 28/12/2020

Publication costs for this article were supported by ecancer (UK Charity number 1176307).

Copyright: (c) the authors; licensee ecancermedicalscience. This is an Open Access article distributed under the terms of the Creative Commons Attribution License (http:// creativecommons.org/licenses/by/3.0), which permits unrestricted use, distribution, and reproduction in any medium, provided the original work is properly cited. 


\section{Background}

Cervical cancer (CC) is the most common gynaecological cancer. Ninety-nine percent of all cases are linked to infection with high-risk human papillomaviruses (HPVs) which may be transmitted through sexual contact [1]. CC ranks fourth among the common cancers in women worldwide; only breast, colorectal and lung cancers are more common [2]. Of the 570,000 cases of CC diagnosed globally in 2018, there were 311,000 deaths (85\% of which were from developing countries). This makes it a major public health problem with a predisposition for middle-aged women in resource constrained countries [2]. Most of these deaths are largely preventable with access to comprehensive cervical cancer prevention (CCP) and control programmes which improve uptake of HPV vaccination among young girls, screening all at-risk women and treating pre-cancerous lesions [3].

The incidence of CC is disproportionately increased in developing countries. In Nigeria, 53.3 million women are estimated to be at risk of developing CC with a national standardised prevalence rate of 33.0 per 100,000 [4]. Many factors such as sexually transmitted infections, reproductive factors, hormonal influences, genetic and host factors have been implicated in the occurrence of CC. Complications associated with CC arise due to late reporting, ignorance and cultural issues relating to cervical cancer screening (CCS) [5, 6].

Regular screening has been shown to effectively detect early disease. Furthermore, the HPV vaccination has also contributed to a decline in the incidence rate of CC. However, several studies have reported that the awareness and uptake of CCS services has remained poor in developing countries despite its availability [6-8]. Provider collected or self-collected HPV testing, cytology-based Papanicolaou smear (Pap smear) and visual inspection with acetic acid (VIA) are common methods of CCS. Self-collected HPV testing and VIA are the most costeffective and should be made readily available in low and middle income countries (LMICs) [9-11].

Inadequate knowledge about CC, lack of familiarity with the concept of prevention, the geographical and economic inaccessibility of care, the poor quality of services and lack of support from husbands and relatives have been identified as major hindrances to CCS [12]. Interestingly, studies in LMICs have shown that knowledge and awareness alone do not necessarily influence uptake of CCS [13-15]. In Nigeria, for instance, despite many campaigns, CCS modalities are hardly utilised [14, 15].

Pregnant women are a sexually active cohort who should ideally have been integrated into CCS schedules in most cases. For those who either have not had any or have a deficient screening history, studies done in North America have shown that pregnant women are still eligible for screening $[16,17]$. Health talks on CC during antenatal visits can help bridge the communication gap that is responsible for the poor knowledge of CC and CCP. So far in Nigeria, there are few studies that have assessed the knowledge of CC and attitude towards its screening among pregnant women alone [18]. Most of the previous studies were either hospital or community-based surveys of non-pregnant women $[6,15,19]$. Interviewing pregnant women in antenatal clinics is an opportunity to access a representative sample of sexually active women. Therefore, this study aims to assess the determinants of knowledge of CC among antenatal attendees, their attitude towards CCS and practice of screening and HPV vaccination as methods to prevent CC.

\section{Methods}

\section{Study setting and design}

This was a facility-based cross-sectional study among pregnant women recruited from the antenatal clinic of the University College Hospital, Ibadan, Oyo State. This Tertiary centre provides care to about 3,000 pregnant women annually.

\section{Study population and eligibility criteria}

The study enrolled consenting pregnant women between the ages of 18 and 45 years by simple random sampling. Women who presented with obstetric emergencies or did not give their consent were excluded from the study. 


\section{Sample size}

The sample size was calculated using a single population proportion formula. Using a $27.7 \%$ proportion (the number of correspondents who has adequate knowledge of CC in a similar study) [20], 95\% confidence interval, 5\% margin of error and an annual population of 3,000 antenatal attendees, the minimum sample size of 276 were derived. Using a non-response rate of $10 \%$, a final sample size of 303 was used.

\section{Data collection}

A self-administered, pre-tested structured questionnaire adapted from a similar study [20] was used to obtain information about the sociodemographic characteristics, knowledge of risk factors, symptoms and prevention of CC, attitude towards CCS and uptake among the women.

\section{Statistical analysis}

The data was analysed using the Statistical Package for Social Sciences (SPSS) version 21 (Released 2012. IBM SPSS Statistics for Windows, Version 21.0, Armonk, NY: IBM Corp). Descriptive statistics were conducted for all relevant data. Categorical variables were explored using chi-square test and the independent variables with significant associations ( $p$-value $<0.05$ ) entered into logistic regression analysis to determine factors associated with knowledge of CC, attitude towards CCS and practice of CCP. Adopting a similar scoring system used in assessing CC knowledge [20], each correctly identified symptom or risk factor was assigned a score of 1, and a score of zero was assigned to an incorrect or 'I don't know' response. The maximum obtainable score for CC knowledge was 25. Using the adopted scoring system [20], women who scored less than or equal to 13 were regarded as having poor knowledge while those who scored over 13 were considered as having good knowledge. Positive attitude towards screening was defined as willingness of the women to be screened for the CC while good practice of CCP was determined if they had undergone the screening for CC and/or received HPV vaccine.

\section{Ethical considerations}

Ethical approval was obtained from the University of Ibadan (UI)/University College Hospital (UCH) Ethics committee with assigned number UI/EC/20/0256.

\section{Results}

Three hundred and three pregnant women participated in the study; however, 287 responses were adequate giving a response rate of $94.7 \%$. Their mean age was $30.62 \pm 4.5$ years and $65.9 \%$ were between 26 and 35 years. Majority (83.3\%) had a tertiary level of education and about half (49.8\%) were employed (Table 1).

Three-fifths (60.6\%) of the women had good knowledge of CC while 58.0\% reported it to be a common malignancy. Health workers were the most common (49.4\%) source of information. Although about half (47.4\%) of the women had heard about CCS, a higher proportion (75.6\%) were willing to undergo CCS thereby exhibiting positive attitude towards screening. Only 48 (16.7\%) women reported that they are susceptible to CC. For the others, some of the reasons for the non-susceptibility were 'I have only one sexual partner' in 95 ( $39.7 \%$ ) and 'I am spiritually protected' in 39 (16.3\%) (Table 2).

About 136 (47.4\%) had heard about CCS but only 27 (9.4\%) ever had a form of screening in the past. Pap smear was the most common (70.4\%) screening modality. The main reasons for undergoing screening were a 'health providers request' (18.5\%) or because 'it was free' ( $22.2 \%)$. Of the 90.6\% who never had any form of CCS, 33.8\% reported that it was because 'health provider did not request for it', $25 \%$ because they were 'not experiencing symptoms' and $11.9 \%$ thought 'I cannot have cervical cancer'. Seventy-two women (25\%) had heard of HPV vaccination and 10 (3.5\%) had received it previously. None of the women who had received HPV vaccine had been screened for CC. Of the 25 women who had a child above 9 years, only 1 (4\%) child had received the HPV vaccine. Only 2 in 10 women knew the HPV vaccine could be received by both boys and girls. One hundred and sixty-four (57.1\%) women were willing to receive the HPV vaccine or recommend it to family and friends (Table 2 ). 
Table 1. Sociodemograpic characteristics of the antenatal attendees.

\begin{tabular}{|l|c|}
\hline Variables & Frequency $(\%) \mathbf{n}=\mathbf{2 8 7}$ \\
\hline Age (years) & $39(13.6)$ \\
$\leq 25$ & $189(65.9)$ \\
$26-35$ & $59(20.6)$ \\
$>35$ & $30.62 \pm 4.5$ \\
Mean \pm SD & \\
\hline Marital status & $21(7.3)$ \\
Single & $266(92.7)$ \\
Married & \\
\hline Ethnicity & $245(85.4)$ \\
Yoruba & $26(9.1)$ \\
Igbo & $3(1.0)$ \\
Hausa & $13(4.5)$ \\
Others & \\
\hline Level of education & $3(1.0)$ \\
None & $2(0.7)$ \\
Primary & $43(15.0)$ \\
Secondary & $239(83.3)$ \\
Tertiary & \\
\hline Employment status & $143(49.8)$ \\
Employed & $112(39.0)$ \\
Self-employed & $32(11.1)$ \\
Unemployed & \\
\hline Religion & $210(73.2)$ \\
Christianity & $77(26.8)$ \\
Islam &
\end{tabular}

Table 2. Attitude towards CCP and uptake of screening and HPV vaccination.

\begin{tabular}{|l|c|}
\hline \multicolumn{1}{|c|}{ Items } & Frequency (\%) \\
\hline Are you susceptible to cancer of the cervix? $(n=287)$ & $48(16.7)$ \\
\hline Reasons for assuming non-susceptibility $(\boldsymbol{n}=\mathbf{2 3 9})$ & $95(39.7)$ \\
\hline I have only a sexual partner & $14(5.9)$ \\
\hline I am immune & $39(16.3)$ \\
\hline I am spiritually protected & $87(36.4)$ \\
\hline I don't know & $27(9.4)$ \\
\hline Ever had screening for CC & $19(70.4)$ \\
\hline Which test was done? $(\boldsymbol{n}=27)$ & $3(11.1)$ \\
\hline Pap smear & $4(14.8)$ \\
\hline HPV test & $1(3.7)$ \\
\hline Visual inspection test & \\
\hline Pap smear and HPV test & \\
\hline
\end{tabular}


Table 2. Attitude towards CCP and uptake of screening and HPV vaccination. (Continued)

\begin{tabular}{|c|c|}
\hline \multicolumn{2}{|l|}{ How many times have you done the test? } \\
\hline 1 & $19(70.4)$ \\
\hline 2 & $7(25.9)$ \\
\hline 4 & $1(3.7)$ \\
\hline \multicolumn{2}{|l|}{ Reasons for having the screening test $(n=27$ ) } \\
\hline Health providers request & $5(18.5)$ \\
\hline It was free & $6(22.2)$ \\
\hline Part of a general screening & $3(11.1)$ \\
\hline Felt like doing it & $13(48.1)$ \\
\hline \multicolumn{2}{|l|}{ Reasons for not having the screening test $(n=260)$} \\
\hline Unaware of the screening availability & $44(16.9)$ \\
\hline Unaware of facilities rendering the service & $17(6.5)$ \\
\hline No experiencing symptoms & $65(25.0)$ \\
\hline Feel it is expensive & $19(7.3)$ \\
\hline Health provider did not request for it & $88(33.8)$ \\
\hline Never thought of it & $52(20.0)$ \\
\hline I cannot have CC & $31(11.9)$ \\
\hline I need my husband's approval & $9(3.5)$ \\
\hline Ever received the HPV vaccine? & $10(3.5)$ \\
\hline \multicolumn{2}{|l|}{ Who recommended it? } \\
\hline Health practitioner & $8(80.0)$ \\
\hline Self & $2(20.0)$ \\
\hline Have a child above 9 years who has received the HPV vaccine $(n=25)$ & $1(4.0)$ \\
\hline Willing to undergo CCS & $217(75.6)$ \\
\hline $\begin{array}{l}\text { Willing to receive the HPV vaccine or recommend it to family and } \\
\text { friends }\end{array}$ & $164(57.1)$ \\
\hline Will accept the vaccine if it is free & $253(88.2)$ \\
\hline Will have a Pap smear if it is free & $253(88.2)$ \\
\hline \multicolumn{2}{|l|}{ Who should receive the HPV vaccine? } \\
\hline Girls & $219(76.3)$ \\
\hline Boys & $4(1.4)$ \\
\hline Both & $52(18.1)$ \\
\hline Nobody & $12(4.2)$ \\
\hline
\end{tabular}

Age $(p=0.015)$ and level of education $(p=0.029)$ were associated with good knowledge of CC. None of the demographic characteristics was associated with increased odds of having good knowledge of CC on multivariate regression analysis (Table 3).

The level of education ( $p=0.001)$ and knowledge of CC ( $p=0.003$ ) were associated with the women's attitude towards screening while knowledge of CC ( $p<0.001)$ was the only significant factor associated with their practice of CCP (Table 4). 
Table 3. Bivariate and multivariate analysis of respondents' characteristics with knowledge of CC.

\begin{tabular}{|c|c|c|c|c|c|}
\hline \multirow{2}{*}{ Variables } & \multicolumn{2}{|c|}{ Knowledge of CC } & \multirow{2}{*}{$X^{2}, p$-value } & \multirow{2}{*}{ OR $(95 \% \mathrm{Cl})$} & \multirow{2}{*}{$p$-value } \\
\hline & Poor & Good & & & \\
\hline \multicolumn{6}{|l|}{ Age (years) } \\
\hline$<25$ & $7(6.2)$ & $32(18.3)$ & \multirow[t]{3}{*}{$8.43,0.015$} & $4.220(0.646-27.545)$ & 0.133 \\
\hline $26-35$ & $80(71.4)$ & $109(62.3)$ & & $3.163(0.652-15.346)$ & 0.153 \\
\hline$>35$ & $25(22.3)$ & $34(19.4)$ & & 1 & \\
\hline \multicolumn{6}{|l|}{ Marital status } \\
\hline Married & $104(92.9)$ & $162(92.6)$ & \multirow[t]{2}{*}{$0.008,1.000$} & 0.449 (0.143-1.415) & 0.172 \\
\hline Single & $8(7.1)$ & $13(7.4)$ & & 1 & \\
\hline \multicolumn{6}{|l|}{ Level of education } \\
\hline Tertiary & $100(89.3)$ & $139(79.4)$ & \multirow[t]{2}{*}{$4.76,0.029$} & $0.148(0.016-1.366)$ & 0.092 \\
\hline Secondary or lower & $12(10.7)$ & $36(20.6)$ & & 1 & \\
\hline \multicolumn{6}{|l|}{ Employment status } \\
\hline Unemployed & $9(8.0)$ & $23(13.1)$ & \multirow[t]{3}{*}{$2.74,0.254$} & $0.588(0.242-1.428)$ & 0.241 \\
\hline Self-employed & $49(43.8)$ & $63(36.0)$ & & $0.574(0.232-1.423)$ & 0.231 \\
\hline Employed & $54(48.2)$ & $89(50.9)$ & & 1 & \\
\hline \multicolumn{6}{|c|}{ Number of antenatal visits } \\
\hline Less or equal to 4 & $70(62.5)$ & $114(65.1)$ & \multirow[t]{2}{*}{$0.21,0.649$} & $1.184(0.690-2.032)$ & 0.540 \\
\hline More than 4 & $42(37.5)$ & $61(34.9)$ & & 1 & \\
\hline \multicolumn{6}{|c|}{ Perceived susceptibility to CC } \\
\hline Yes & $16(14.3)$ & $32(18.3)$ & \multirow[t]{2}{*}{$0.79,0.376$} & $1.343(0.699-2.581)$ & 0.377 \\
\hline No & $96(85.7)$ & $143(81.7)$ & & 1 & \\
\hline
\end{tabular}

The women with tertiary education were more likely $(\mathrm{OR}=2.140,95 \% \mathrm{Cl}=1.166-4.979)$ to have a positive attitude towards screening than those with 'secondary or lower' level of education. While those with poor knowledge of the disease had lower odds (OR $=0.532,95 \%$ $\mathrm{Cl}=0.291-0.972$ ) of having a positive attitude towards screening compared to those with good knowledge. Knowledge of CC was the only determinant of the practice of CCP. The women who had poor knowledge of the disease were less likely $(\mathrm{OR}=0.061,95 \% \mathrm{Cl}=0.008-0.471)$ to practice CCP than those with good knowledge (Table 5).

\section{Discussion}

This study is one of the few that have surveyed antenatal attendees on CC and CCP. About two-thirds exhibited good knowledge of CC in this study and this was a contrast to the poor knowledge recorded among participants in community based and hospital based studies in Africa [6-8, 21-23]. In a similar survey of antenatal attendees in South east Nigeria, the women were identified as having poor knowledge of CC [24]. Our finding may not be unconnected to the fact that a greater proportion of women in our study had tertiary level of education. Information about this disease was mostly through health workers, a finding which corroborates the reports from a hospital based survey of pregnant and non-pregnant women in Lagos, Nigeria [21]. However, the media was the main source of information in a community based survey of rural women also in Lagos, Nigeria [25]. Quality sources of information are necessary to nullify the many myths African women have about CC [25]. In a qualitative cross-sectional study in Northern Nigeria, the knowledge about the aetiology and risk factors of CC was poor among participants albeit with adequate awareness of the disease. The women thought the use of herbal concoctions and poor personal 
and environmental hygiene were the risk factors associated with CC [26]. Our study showed that age and level of education were associated with knowledge levels. However, multivariate analysis revealed that none of the demographic factors were associated with increased odds of having good knowledge of CC.

Most of the women surveyed did not consider themselves at risk for CC. The belief that non-susceptibility is due to spiritual protection is extremely flawed but not new [27]. If women feel shielded by their spirituality, then it means their understanding of the aetiology of the disease is poor and this may mitigate against CCP. Non-susceptibility is also reported by majority of the women of reproductive age in the southern region of the country who however acknowledge that CCS is beneficial [28]. Despite poor uptake, an overwhelming majority believe that CCS is important [29].

Although half of the respondents in our study were aware of CCS, only 1 in 10 of the women had ever been screened. The Pap smear was the most commonly used form of CCS while the combination of Pap smear and HPV testing was the least utilised. In Nigeria, the proportion of women who have been screened for $\mathrm{CC}$ has been consistently low [25]. These poor indices have been recorded in both rural and urban areas, across various geographical locations. However, in some of the studies where the awareness levels were high, it did not translate to adequate knowledge levels or uptake of CCS [21, 26, 30, 31]. A Pap smear is a highly sensitive and specific method that has been used for decades to detect pre-cancerous lesions of cervix [32]. The World Health Organization recommends the screen-and-treat approach with the preferred screening modality to include HPV testing except in environments without enough resources to test for the virus. In these areas, VIA is more cost-effective and treatment should be arranged at the same contact [33]. Another advantage of this screen-and-treat approach is that it reduces the incidence of loss to follow-up.

Table 4. Bivariate analysis of respondents' characteristics with attitude towards CCS and practice of CCP.




Table 5. Multivariate analysis of characteristics against attitude towards CCS and practice of CCP.

\begin{tabular}{|c|c|c|c|c|}
\hline & \multicolumn{2}{|c|}{ Positive attitude to CCS } & \multicolumn{2}{|c|}{ Practice of CCP } \\
\hline & OR $(95 \% \mathrm{Cl})$ & $p$-value & OR $(95 \% \mathrm{Cl})$ & $p$-value \\
\hline \multicolumn{5}{|l|}{ Age (years) } \\
\hline$\leq 25$ & $0.791(0.302-2.069)$ & 0.632 & $4.656(0.466-46.702)$ & 0.191 \\
\hline $26-35$ & $0.564(0.28-1.124)$ & 0.104 & $1.339(0.525-3.417)$ & 0.541 \\
\hline$>35$ & 1 & & 1 & \\
\hline \multicolumn{5}{|l|}{ Marital status } \\
\hline Married & $1.545(0.555-4.295)$ & 0.405 & $0.798(0.145-4.38)$ & 0.795 \\
\hline Single & 1 & & 1 & \\
\hline \multicolumn{5}{|l|}{ Level of education } \\
\hline Tertiary & $2.410(1.166-4.979)$ & 0.018 & $2.747(0.308-24.534)$ & 0.366 \\
\hline Secondary or lower & 1 & & 1 & \\
\hline \multicolumn{5}{|l|}{ Employment status } \\
\hline Unemployed & $0.911(0.356-2.334)$ & 0.847 & $0.581(0.205-4.310)$ & 0.462 \\
\hline Self-employed & $0.656(0.252-1.711)$ & 0.389 & $0.337(0.089-1.280)$ & 0.170 \\
\hline Employed & 1 & & 1 & \\
\hline \multicolumn{5}{|c|}{ Number of antenatal visits } \\
\hline Less or equal to 4 & $1.270(0.695-2.319)$ & 0.437 & $0.611(0.246-1.521)$ & 0.290 \\
\hline More than 4 & 1 & & 1 & \\
\hline \multicolumn{5}{|l|}{ Knowledge of CC } \\
\hline Poor & $0.532(0.291-0.972)$ & 0.040 & $0.061(0.008-0.471)$ & 0.007 \\
\hline Good & 1 & & 1 & \\
\hline
\end{tabular}

The women studied in our centre had not been screened for CC mainly because no health provider requested for it. Health providers played a vital role in promoting uptake of screening modalities among those who had been screened in the past. This pattern has also been documented in other studies [21,34]. Health providers are the major influencers of the knowledge of CC and the uptake of CCS, while negative behaviours by health providers towards at-risk women have been described as a deterrent to the uptake of CCS [35]. These workers should be trained consistently to deliver health talks to individuals, groups or mass media and to perform thorough physical examinations so as to identify at-risk women and provide screening modalities [23]. The fact that a quarter of the respondents felt they did not need screening because they had no symptoms also implies that they do not understand the concept of CCP, the insidious nature of the disease and the fact that overt malignancy can be quite devastating. It is surprising that another group of women just concluded that they could not have CC even with no scientific evidence.

Majority of the women were willing to be screened for CC. This finding is in keeping with various reports in Nigeria [21, 25, 34, 36]. Multivariate analysis revealed that the willingness to undergo screening in our study was associated with knowledge of the disease and education status. Those with good knowledge of the disease were two times more likely to exhibit willingness for screening compared to those with poor knowledge while the women with tertiary education were more than two times more likely to be willing to be screened compared to those with secondary education or less. Other studies have shown that women in Southwest Nigeria are willing to undergo CCS [21, 25]. 
There was a poor uptake of Pap smear and HPV vaccine among the women surveyed. Those with good knowledge were about 16 times more likely to practice either form of CCP as against women with poor knowledge. Nigeria has a remarkably low level of uptake of Pap smear and HPV vaccination; [29, 37, 38] other African countries are not quite different [13, 39, 40]. It is important to increase the awareness of CCP in order to promote its practice [31]. Furthermore, the government has a role to play by establishing organised screening centres and adopting protocols that improve uptake [37]. Factors like inability to afford the cost of screening, not knowing where and how to access screening services, nonchalant attitude to one's health are some reasons identified for poor uptake of screening [5].

Of the 25 women who had children above 9 years of age, only one woman reported her daughter had received the HPV vaccine and thus the burden of CC on the next generation can be implied. Studies across Africa have shown that many women and young girls are not receiving the HPV vaccine $[11,41]$. Some factors like fear, cost of vaccine and lack of multiple sexual partners or lack of sexual activity have been identified as barriers to the uptake of HPV vaccine [41]. The willingness to receive HPV vaccine recorded in a little over half of the respondents is also suboptimal and may be a reflection of myths associated with vaccination. The fact that many more women in our study were willing to receive HPV vaccine if it was free signifies that cost may prevent some from receiving the vaccine.

While pregnant women are obviously at risk for CC, there is a paucity of studies regarding this subject matter among them. This group of women is accessible and they can be surveyed as an indirect measure of CCS in Nigerian women. This study did not assess if the women had received prior information/education pertaining $\mathrm{CC}$ and its screening during previous antenatal clinic visits. This aspect can be considered when designing similar research protocols in future studies. Also, a mixed methods approach to include one-on-one interviews may elicit myths or misconceptions about CC and other barriers to prevention.

\section{Conclusion}

Many of the women surveyed demonstrated good knowledge of CC. However, the uptake of CCS and vaccination against HPV were grossly inadequate. Tertiary education and good knowledge of CC were determinants of positive attitude towards CCS while good knowledge of the disease influenced the practice of both screening and HPV vaccination as methods to prevent CC.

In Nigeria, the burden of CC can be reduced if women are educated and health care providers challenged to recommend CCS and HPV vaccination.

\section{Conflicts of interest}

The authors declare that they have no competing interests.

\section{Funding}

None.

\section{Acknowledgments}

The authors acknowledge the participants in this study for taking time to complete the questionnaires and appreciate the contribution of the staff in the Antenatal Clinics of the University College Hospital, Ibadan. 


\section{References}

1. Ferlay J, Colombet M, and Soerjomataram I, et al (2019) Estimating the global cancer incidence and mortality in 2018: GLOBOCAN sources and methods Int J Cancer 144(8) 1941-1953 https://doi.org/10.1002/ijc.31937

2. Arbyn M, Weiderpass E, and Bruni L, et al (2020) Estimates of incidence and mortality of cervical cancer in 2018: a worldwide analysis Lancet Glob Health 8(2) e191-e203 https://doi.org/10.1016/S2214-109X(19)30482-6 PMCID: 7025157

3. Balog JE (2009) The moral justification for a compulsory human papillomavirus vaccination program Am J Public Health 99(4) 616-622 https://doi.org/10.2105/AJPH.2007.131656 PMID: 19197085 PMCID: 2661471

4. Ilevbare OE, Adegoke AA, and Adelowo CM (2020) Drivers of cervical cancer screening uptake in Ibadan, Nigeria Heliyon 6(3) e03505 https://doi.org/10.1016/j.heliyon.2020.e03505 PMID: 32190755 PMCID: 7068050

5. Ndikom CM and Ofi BA (2012) Awareness, perception and factors affecting utilization of cervical cancer screening services among women in Ibadan, Nigeria: a qualitative study Reprod Health 9(11) 1-8 https://doi.org/10.1186/1742-4755-9-11

6. Amu E, Ndugba S, and Olatona F (2019) Knowledge of cervical cancer and attitude to cervical cancer screening among women in somolu local government area, Lagos, keywords: cervical screening J Community Med Prim Heal Care 31(1) 76-85

7. Bakari M, Takai IU, and Bukar M (2015) Awareness and utilization of papanicoloau smear among health care workers in Maiduguri, Nigeria Niger J Basic Clin Sci 12(1) 34-38 https://doi.org/10.4103/0331-8540.156682

8. Mengesha A, Messele A, and Beletew $B$ (2020) Knowledge and attitude towards cervical cancer among reproductive age group women in Gondar town, North West Ethiopia BMC Public Health 20(1) 1-10 https://doi.org/10.1186/s12889-020-8229-4

9. Van Den Akker-Van Marle ME, Van Ballegooijen M, and Van Oortmarssen GJ, et al (2002) Cost-effectiveness of cervical cancer screening: comparison of screening policies J Natl Cancer Inst 94(3) 193-204 https://doi.org/10.1093/jnci/94.3.193 PMID: 11830609

10. Goldie SJ, Gaffikin L, and Goldhaber-Fiebert JD, et al (2005) Cost-effectiveness of cervical-cancer screening in five developing countries N Engl J Med 353(20) 2158-2168 https://doi.org/10.1056/NEJMsa044278 PMID: 16291985

11. Mezei AK, Armstrong HL, and Pedersen HN, et al (2017) Cost-effectiveness of cervical cancer screening methods in low- and middleincome countries: a systematic review Int J Cancer 141(3) 437-446 https://doi.org/10.1002/ijc.30695 PMID: 28297074

12. Nene B, Jayant $K$, and Arrossi S, et al (2007) Determinants of women's participation in cervical cancer screening trial Maharashtra, India Bull World Health Organ 85 264-272 https://doi.org/10.2471/BLT.06.031195 PMID: 17546307 PMCID: 2636321

13. Gatachew S, Gatechew E, and Gizaw M, et al (2019) Cervical cancer screening knowledge and barriers among women in Addis Ababa, Ethiopia PLoS One 14(5) 1-13

14. Ifemelumma CC, Anikwe CC, and Okorochukwu BC, et al (2019) Cervical cancer screening: assessment of perception and utilization of services among health workers in low resource setting Int J Reprod Med 2019 1-8 https://doi.org/10.1155/2019/6505482

15. Ijezie AE, Johnson OE, and State Al, et al (2019) Knowledge of cervical cancer and the uptake of the papanicolaou smear test among public secondary school teachers in Akwa Ibom Niger Med J 60(5) 245-251 https://doi.org/10.4103/nmj.NMJ_120_19 PMID: 31844353 PMCID: 6900900

16. Stonehocker J (2013) Cervical cancer screening in pregnancy Obstet Gynecol Clin North Am 40(2) 269-282 https://doi.org/10.1016/j. ogc.2013.03.005 PMID: 23732031

17. Rerucha C, Rebecca C, and Wheeler V (2018) Cervical cancer screening Am Fam Physician 97(7) 441-448 PMID: 29671553

18. Ingwu JA (2016) Knowledge and screening practices of cervical cancer among pregnant women attending antenatal clinic in tertiary hospitals in Enugu, South-Eastern Nigeria J Cancer Tumor Int 4(2) 1-9 https://doi.org/10.9734/JCTI/2016/27118 
19. Okunade KS, Sunmonu O, and Osanyin GE, et al (2017) Knowledge and acceptability of human papillomavirus vaccination among women attending the gynaecological outpatient clinics of a university teaching hospital in Lagos, Nigeria J Trop Med 2017 1-6 https:// doi.org/10.1155/2017/8586459

20. Okunowo AA, Daramola ES, and Soibi-harry AP, et al (2018) Women 's knowledge of cervical cancer and uptake of Pap smear testing and the factors in fl uencing it in a Nigerian tertiary hospital J Cancer Res Pract 5(3) 105-111 https://doi.org/10.1016/j.jcrpr.2018.02.001

21. Okunowo AA, Daramola ES, and Soibi-harry AP, et al (2018) Women's knowledge of cervical cancer and uptake of Pap smear testing and the factors influencing it in a Nigerian tertiary hospital J Cancer Res Pract 5(3) 105-111 https://doi.org/10.1016/j.jcrpr.2018.02.001

22. Shiferaw S, Addissie A, and Gizaw M, et al (2018) Knowledge about cervical cancer and barriers toward cervical cancer screening among HIV-positive women attending public health centers in Addis Ababa city, Ethiopia Cancer Med 7(3) 903-912 https://doi.org/10.1002/ cam4.1334 PMID: 29441700 PMCID: 5852347

23. Abril EP, Kupczyk M, and Zwicke GL (2015) Mapping the health communication infrastructure in rural Senegal: an assessment to support cervical cancer screening J Appl Commun Res 43(2) 242-262 https://doi.org/10.1080/00909882.2015.1019545

24. Ingwu J (2016) Knowledge and screening practices of cervical cancer among pregnant women attending antenatal clinic in tertiary hospitals in Enugu, South-Eastern Nigeria J Cancer Tumor Int 4(2) 1-9 https://doi.org/10.9734/JCTI/2016/27118

25. Oluwole EO, Mohammed AS, and Akinyinka MR, et al (2017) Cervical cancer awareness and screening uptake among rural women in Lagos, Nigeria J Community Med Prim Heal Care 29(1) 81-88

26. Yahya A and Mande A (2019) Awareness and knowledge of cervical cancer and its screening methods among women attending primary healthcare centers in Zaria, North-Western, Nigeria Trop J Obstet Gynaecol 36 271-276. https://doi.org/10.4103/TJOG.TJOG_26_19

27. Olubodun T, Odukoya OO, and Balogun MR (2019) Knowledge, attitude and practice of cervical cancer prevention, among women residing in an Urban slum in Lagos, South West, Nigeria Pan Afr Med J 32 1-10 https://doi.org/10.11604/pamj.2019.32.130.14432

28. Olubodun T, Odukoya O, and Balogun M (2019) Knowledge, attitude and practice of cervical cancer prevention, among women residing in an urban slum in Lagos, South West, Nigeria Pan Afr Med J 32(130) 1-10 https://doi.org/10.11604/pamj.2019.32.130.14432

29. Anyebe E, Opaluwa S, and Muktar H, et al (2014) Knowledge and practice of cervical cancer screening amongst nurses in Ahmadu Bello university teaching hospital Zaria Res Humanit Soc Sci 4(27) 33-40

30. Ingwu J (2017) Knowledge and screening practices of cervical cancer among pregnant women attending antenatal clinic in tertiary hospitals in Enugu, South-Eastern knowledge and screening practices of cervical cancer among pregnant women attending antenatal clinic in ter J Cancer Tumor Int 4(2) 1-9 https://doi.org/10.9734/JCTI/2016/27118

31. Idowu A, Olowookere SA, and Fagbemi AT, et al (2016) Determinants of cervical cancer screening uptake among women in Ilorin, North Central Nigeria: a community-based study J Cancer Epidemiol 20166469240 https://doi.org/10.1155/2016/6469240 PMID: 26880916 PMCID: 4736774

32. Verma A, Verma S, and Vashist S, et al (2017) A study on cervical cancer screening in symptomatic women using pap smear in a tertiary care hospital in rural area of Himachal Pradesh, India Middle East Fertil Soc J 22(1) 39-42 https://doi.org/10.1016/j.mefs.2016.09.002

33. WHO (2013) Guidelines for screening and treatment of precancerous lesions for cervical cancer prevention [Internet] (Geneva: WHO Guidelines) [http://www.who.int/reproductivehealth/publications/cancers/screening_and_treatment_of_precancerous_lesions/en/ index.html]

34. Awosan KJ, Hassan M, and Ibrahim BM (2018) Knowledge of cervical cancer and uptake of pap smear test and human papillomavirus vaccination among gynecologic clinic attendees in Sokoto Int J Sci Study 6(5) 52-58

35. Nwobodo $\mathrm{H}$ and Ba-Break M (2016) Analysis of the determinants of low cervical cancer screening uptake among Nigerian women $\mathrm{J}$ Public Health Afr 6(2) 12-19 
36. Ndikom CM, Ofi BA, and Folashade O (2014) Willingness to utilize cervical cancer screening services among, antenatal clinic attendees in selected hospitals in Ibadan, Nigeria J Women's Health 3(3) 1-5 https://doi.org/10.4172/2325-9795.1000149

37. Urom G, Omabe E, and Okoli N, et al (2019) Cervical cancer: risk factors and uptake of screening among expectant mothers in Abakaliki Niger J Surg Sci 27(2) 37-40

38. Dike FM and O El (2017) Factors influencing uptake of cervical cancer screening among female health workers in university of port harcourt teaching hospital, Rivers State J Health Sci Res 2(1) 1-9 https://doi.org/10.18311/jhsr/2017/8530

39. Gatumo M, Gacheri S, and Sayed AR, et al (2018) Women's knowledge and attitudes related to cervical cancer and cervical cancer screening in Isiolo and Tharaka Nithi counties, Kenya: a cross-sectional study BMC Cancer 18(1) 1-9 https://doi.org/10.1186/s12885018-4642-9

40. Nega AD, Woldetsadik MA, and Gelagay AA (2018) Low uptake of cervical cancer screening among HIV positive women in Gondar University referral hospital, Northwest Ethiopia: cross-sectional study design BMC Womens Health 18(87) 1-7 https://doi.org/10.1186/ s12905-018-0579-z

41. Francis SA, Nelson J, and Liverpool J, et al (2010) Examining attitudes and knowledge about HPV and cervical cancer risk among female clinic attendees in Johannesburg, South Africa Vaccine 28(50) 8026-8032 https://doi.org/10.1016/j.vaccine.2010.08.090 PMID: $\underline{20887829}$ 